\title{
Does TRM Occur in Oceanic Layer 2 Basalts?
}

\author{
J.M. HALL \\ Department of Geology, Dalhousie University, \\ Halifax, Nova Scotia, Canada
}

(Received June 20, 1977)

\begin{abstract}
It is shown that, as a consequence of rapid low temperature oxidation, the magnetization of at least the upper $600 \mathrm{~m}$ of oceanic layer 2 almost everywhere, except immediately adjacent to ridge crests, must be regarded as being chemical remanent rather than thermoremanent in nature. While most magnetic properties are changed drastically as a result of this alteration process, it seems that initial TRM direction is unlikely to be altered by more than $10^{\circ}$, and then only when original magnetizing and dipole fields differ markedly in direction. Increased scatter in direction appears to be a more general consequence of CRM replacement of TRM.
\end{abstract}

\section{Introduction}

The essence of the model of oceanic crust as a recorder of geomagnetic field reversals is in the assumption that field directions are reliably recorded by at least some ocean crust rocks for up to $200 \mathrm{my}$. This assumption can be made with conviction if fairly fine-grained, magnetite bearing rocks are involved, and the initial magnetization is of thermoremanent nature. The last stipulation follows from the well known strong and stable nature of laboratory TRM in the appropriate fine-grained basaltic rocks.

Serious criticism of the model follows if it can be shown that the magnetization of oceanic crustal rocks is not initial thermoremanence, but was acquired by some other process well after initial cooling. A delay in remagnetization of $10^{5}-10^{6} \mathrm{yr}$. in the Neogene could be very serious since a stable direction opposing the initial TRM might be acquired. It is critical to test whether the NRM retains the original TRM direction.

The plan of this paper is first to identify the nature of the magnetization of ocean crust rocks and then to look carefully at the meaning, in terms of geomagnetic field record, of the remanence directions.

\section{Nature of Magnetization of Ocean Crust Rocks}

The nature of the magnetization of upper layer 2 of the oceanic crust, which consists largely of pillow basalts, has become clear from a series of studies extending over the last 15 years. Results to 1970 are summarized in Watkins and PAster (1971) while more recent work is described in Lowrie (1974, 1977). Presently information is available for basalts forming the upper surface of the layer from a wide 
range of geographic locations in all the major oceans, and to a depth of 500 to $600 \mathrm{~m}$ at a limited number of locations in the Atlantic. Basalts which are the least altered contain optically homogeneous iron-titanium oxide magnetic minerals, titanomagnetites, with composition close to $x=0.65$ in $x \mathrm{Fe}_{2} \mathrm{TiO}_{4}(1-x) \mathrm{Fe}_{3} \mathrm{O}_{4}$ (JoHNSON and Hall (in press)). However, in terms of distribution, these little altered basalts are rare, only occurring among the youngest $\left(\simeq 10^{4} \mathrm{yr}\right.$.) pillow flows on ridge crests or in occasional older massive flows (JoHNSON and HALL, op. cit.). Most basalts of layer 2 show optical evidence of alteration, with a range from minor indications of oxidation to almost complete replacement of oxides by silicates. A convenient way to quantify the observed changes is by the degree of cation deficiency of the titanomagnetite. This is obtained, once an $x$ value is known or assumed, from the Curie temperatures of basalt samples or the unit cell edge of separated oxides. Unoxidized or stoichiometric titanomagnetites from layer 2 basalts have Curie temperatures close to $120^{\circ} \mathrm{C}$. This temperature implies an $x$ value of close to 0.65 and a cation deficiency, $z$, of zero. As oxidation proceeds Curie temperature rises continuously to a maximum value of about $420^{\circ} \mathrm{C}$, corresponding to a value of 1.00 , or complete replacement or removal of $\mathrm{Fe}^{2+}$ ions from the titanomagnetite lattice. A number of studies describe the abundance of cation deficient forms compared with stoichiometric forms of titanomagnetite (OzImA and OzIma, 1971; Lowrie et al., 1973a, b). Other studies show that titanomagnetites from basalts forming the upper surface of layer 2 are appreciably cation deficient within a few million years of formation (SCHAEFFER and SCHWARz, 1970; Johnson and ATwater, 1977) while Ryall et al. (1977) show that a high average state of cation deficiency extends to at least $560 \mathrm{~m}$ depth in layer 2 by at the most 3.5 my after crustal formation (Fig. 1).

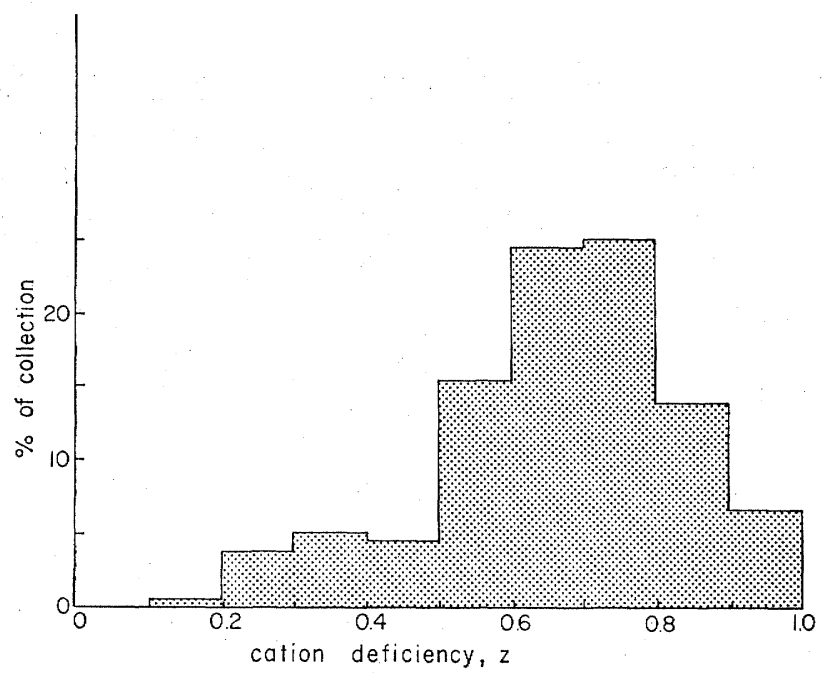

Fig. 1. Distribution of titanomagnetite cation deficiency in 447 oceanic layer 2 basalts sampled during Deep Sea Drilling Project Leg 37. Age range 3.5 to $16 \mathrm{my}$. Depth range 0 to $560 \mathrm{~m}$ sub-basement (from RyAlL et al. 1977). 
The physical and chemical conditions in which cation deficiency is produced in layer 2 basalts seem clear. A combination of in situ temperature measurements, secondary mineral structures, oxygen isotope determinations and laboratory tests of the thermal stability of cation deficient titanomagnetites show that oxidation by sea water at not more than a few tens of degrees centigrade is the only common mechanism (Yeats et al., 1976; Hyndman et al., 1976; Muehlenbachs, 1977).

\section{Magnetic Changes Accompanying Low Temperature Oxidation}

Figure 2 summarizes the evolution of a layer 2 basalt as a magnetic material. Optical mineralogy and thermomagnetic tests show that none or little of the original titanomagnetite remains in oxidized samples. For this reason, it seems necessary to regard the magnetization of the oxidized basalts as a chemical remanence (CRM) as suggested by IRVING et al. (1970) since the oxidation process takes place essentially isothermally at close to ocean bottom temperatures which are well below the Curie temperatures of the titanomagnetites. The presence of thermochemical remanence at depth in the crust is unproven but seems likely.

Figure 3 summarizes the major changes in magnetic properties that accompany increasing titanomagnetite cation deficiency. From the point of view of fidelity in preserving TRM directions we note that a very large decrease in remanence (NRM) intensity occurs during the alteration process. Study of the variation in NRM away from ridge crests, which is likely to be largely dependent on the progress of alteration, suggest that at least a factor of five overall decrease occurs over the full range of $z$ (HALL, 1977).

It must be asked whether such major decrease in remanent intensity can occur without significant change in remanence direction. Several laboratory experiments led to the conclusion that remanence direction might persist unchanged during alteration (Wilson and Smith, 1970; Marshall and Cox, 1971). With increased

THE LIFE HISTORY OF A SUBMARINE BASALT AS A MAGNETIC MATERIAL

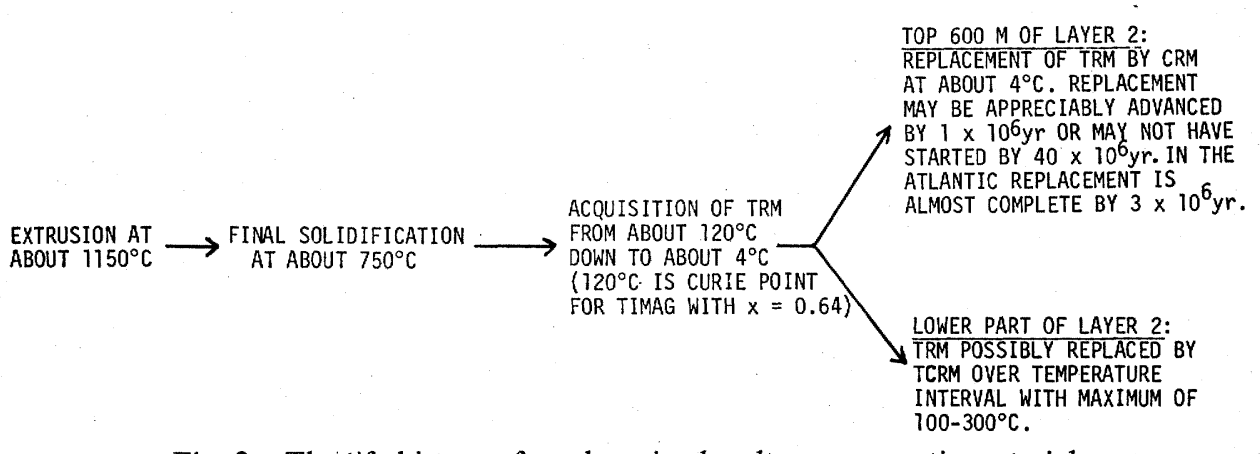

Fig. 2. The life history of a submarine basalt as a magnetic material. 
THE INFLUENCE OF LOW TEMPERATURE OXIDATION ON THE MAGNETIC PROPERTIES OF SUBMARINE BASALTS

PROPERTIES THAT INCREASE IN VALUE AS OXIDATION INCREASES :

PROPERTIES THAT DECREASE IN VALUE AS OXIDATION INCREASES :
CURIE TEMPERATURE: $120^{\circ} \mathrm{C}$ to $420^{\circ} \mathrm{C}$ for $\mathrm{z}=0$ to $\mathrm{z}=1$

MEAN DEMAGNETIZING FIELD (ALSO DEPENDENT ON GRAIN SIZE VARIATION): ABOUT AN ORDER OF MAGNITUDE FROM $z=0$ to $z=1$

NATURAL REMANENCE INTENSITY: ABOUT A FACTOR OF FIVE FROM $z=0$ to $z=1$

$\left.\begin{array}{l}\text { SATURATION MAGNETIZATION } \\ \text { INITIAL SUSCEPTABILTIY }\end{array}\right\} \begin{aligned} & \text { BETWEEN A FACTOR OF FIVE AND AN } \\ & \text { ORDER OF MAGNITUDE FROM } z=0 \text { to } \\ & z=1\end{aligned}$

2 RATIO, PEAK AT ABOUT $z=0.75$

PROPERTY THAT SHOWS A PEA VALUE AT AN INTERMEDIATE OXIDATION LEVEL

Fig. 3. The influence of low temperature oxidation on the magnetic properties of submarine basalts.

knowledge of alteration mechanisms, and, in particular, discovery that the thermal stability of cation deficient titanomagnetites was limited to temperatures below about $135^{\circ} \mathrm{C}$ (Johnson and MerRILL, 1973), the applicability of these experiments to natural conditions came into question. Both studies described laboratory tests carried out at temperatures of up to $600^{\circ} \mathrm{C}$. We know now that these high temperatures lead to phase splitting of cation deficient titanomagnetite (e.g., WAYMAN and EvANS, 1977 ), which is very rare in layer 2 basalts, and so do not represent alteration in natural conditions.

A permissible way to proceed is to make no assumption from laboratory experiments about the possibility of directional change, but instead to look at the results of measurements of collections of layer 2 basalts for evidence that bears on the question. Relevant evidence occurs as alternating field cleaned NRM inclinations for sets of samples from basaltic units forming upper layer 2 in the Atlantic and Pacific. In several instances, twenty or more semioriented (azimuthally unoriented) samples are available from a single lithologic unit (YeAts et al., 1976; Melson et al., 1977). For each set it can be safely assumed that initial magnetization took place sufficiently quickly ( 1 to $100 \mathrm{yr}$.) and that all the samples in the set had the same initial TRM directions. Since systematic alternating field demagnetization has been carried out for all samples, we can be sure that change in cleaned inclination from sample to sample in a set is not the result of the presence of perturbing viscous magnetic components. Finally, as a result of the uneven progress of oxidation in submarine basaltic flows, many of the sets show quite a wide range in titanomagnetite cation deficiency. Plots of the variation of stable inclination with $z$, the degree of cation deficiency will show whether any directional change accompanies low temperature alteration. Figures 4 and 5 illustrate the data. In all cases the spread of inclinations, which is typically close to $20^{\circ}$, in these large sets, yields well confined mean inclinations with 


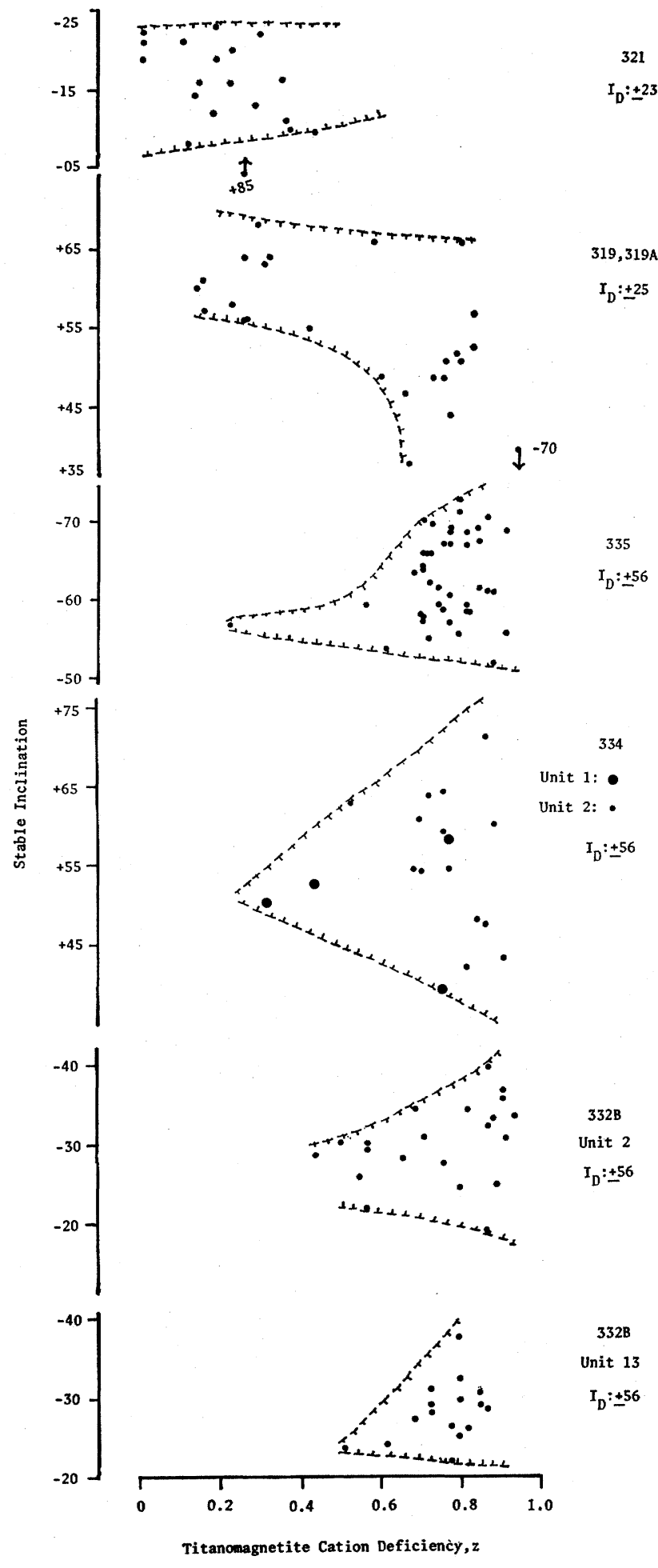

Fig. 4. The variation of stable inclination with degree of titanomagnetic cation deficiency in six oceanic layer 2 basalt units. (The basic data is available in the Initial Reports of the Deep Sea Drilling Project, Leg 34 and 37: YeAts et al., 1976 and MELson et al., 1977.) 


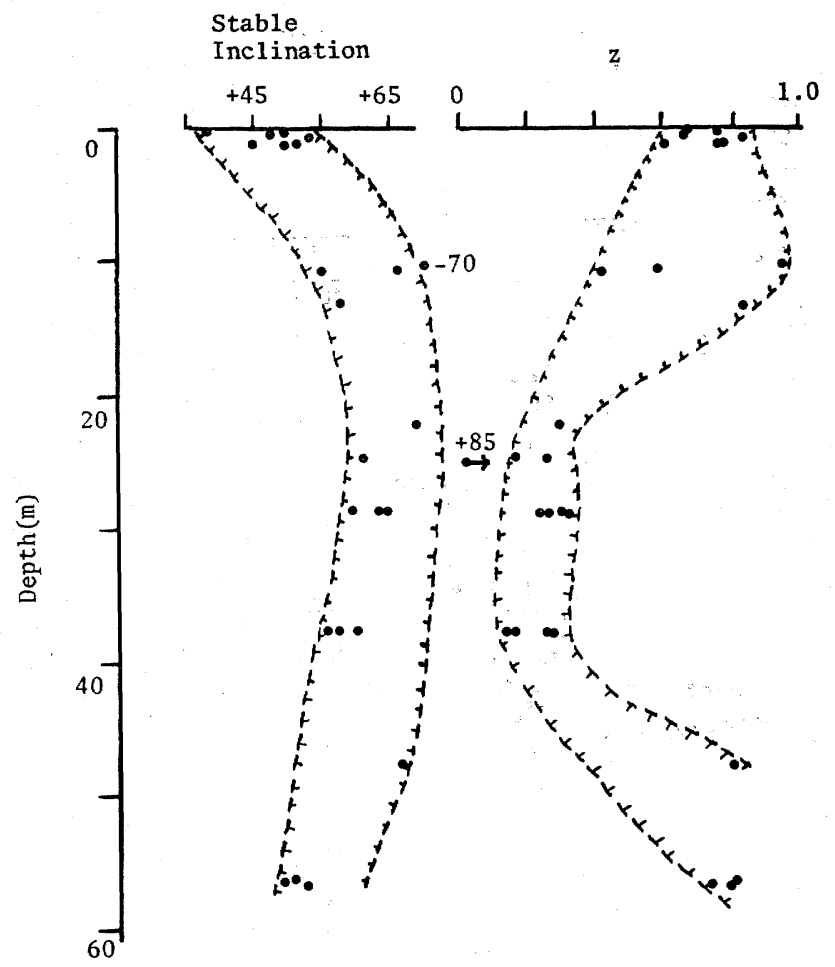

Fig. 5. Variation of stable inclination and titanomagnetite cation deficiency with depth in layer 2 basalts at D.S.D.P. Site 319 (from several sources in YEATS et al., 1976).

standard derivations of the mean value of from $1^{\circ}$ to $4^{\circ}$. At our present level of understanding of paleomagnetic directions, these small uncertainties are interpreted as implying that original TRM inclinations are well preserved in the cleaned NRM inclinations. At the same time, there are strong hints in many of the distributions that cleaned inclinations do vary with $z$. Referring to Fig. 4 we note that:

1) In five of six sets the scatter in inclinations increases with increasing $z$. The sixth set (321) contains only low $z(z \lessgtr 0.4)$ samples and in this respect differs from the other sets which are usually dominated by high $z(z \gtrsim 0.5)$ samples.

2) In two examples $(319,319 \mathrm{~A}$ and 332B, Unit 2$)$ the distribution of points is sufficient to suggest that a small change in average direction occurs as $z$ increases. Approximately ten and six degrees average angular change, respectively, are apparent for the ranges in $z$ involved. These figures are obtained by fitting a smooth curve to average values of stable inclination for cation deficiency intervals of 0.1 . Similar cases might be made for 335 and 332B, Unit 13 but here the forms of the envelopes are determined by single relatively low $z$ value samples.

The data for $319 / 319 \mathrm{~A}$ is shown in a slightly different format in Fig. 5. It is clearly seen that the low $z$ zone in the middle of the sequence corresponds to relatively 
high $\left(+55^{\circ}\right.$ to $\left.+65^{\circ}\right)$ stable inclinations while high $z$ zones above and below correspond to relatively low $\left(+45^{\circ}\right.$ to $\left.+55^{\circ}\right)$ inclinations.

Before considering possible geophysical implications of these variations it is necessary to point out the deficiencies in the data. First, the quality of the data is barely adequate to distinguish the rather small angular changes which may occur as the result of alteration. A reasonable estimate of the average angular uncertainty in a data point is $\pm 5^{\circ}$. Major contributions to this uncertainty are the frequent need to sample slightly barrel-shaped core samples, formed by the breakup and rotation of sections of core during drilling, rather than perfectly cylindrical sections, and in defining cleaned inclinations (HALL and RYALL, 1977). It is only because large numbers of samples are available in each set that trends may be identified at all. Secondly, only one example $(319,319 \mathrm{~A})$ contains samples covering most of the range in $z$ (from $z \sim 0.2$ to $\sim 0.8)$. The low $z$ samples in this set are from massive basalts intercalated between pillow sequences. All the other sets are from pillow sequences and the rapid progress of alteration in lava pillows has left little or no low $z$ material for study.

Explanation of the inclination trends with increasing $z$ may be as follows:

1) Increased scatter in inclination for $z>0.5$ may represent CRM acquisition during the higher degrees of alteration at different times within one polarity epoch or during polarity epochs of different senses. This seems likely to happen since, although alteration is rather quick, being largely completed in 2 to 3 million years, the length of polarity epochs, at least during the young Neogene is an order of magnitude less than these times (Cox, 1969).

It must be emphasized that the tendency for CRM to follow the direction or polarity of the field during acquisition is at best weak and usually the initial magnetizing field direction still dominates.

2) Change in average cleaned inclination with increasing $z$, which occurs in two examples in addition to increased scatter, may be related to marked differences between initial magnetizing and local dipole field inclinations. Thus, an atypically steep initial magnetizing field of between $+55^{\circ}$ and $+65^{\circ}$ inclination is $30^{\circ}$ to $40^{\circ}$ away from the normal dipole field inclination of $+25^{\circ}$ for the site of $319 / 319 \mathrm{~A}$. Again, for 332B, Unit 2, atypically shallow initial magnetizing field inclination of about $+25^{\circ}$ is $30^{\circ}$ away from the normal dipole inclination of $+56^{\circ}$. For both examples the effect of CRM acquisition has been to rotate stable inclinations slightly towards normal dipole field inclinations. Presumably this effect represents in both cases a major part of CRM acquired in normal polarity dipole fields. For the originally reversely magnetized Unit 2 of Hole 332B, of age $3.5 \mathrm{my}$, major alterationinduced magnetic changes took place during the succeeding Gauss normal polarity epoch and this is likely to be the period during which bias in CRM directions towards the normal dipole field occurred. The combined circumstances of non-dipolar TRM inclinations and CRM acquisition during a single polarity epoch have been proposed independently by MERRILL (1975) as optimal for CRM and TRM inclinations to differ. The contribution of the present study is to demonstrate the existence and magnitude of the effect. If tectonic tilting is responsible for the observed shallow stable incli- 
nations for Unit 2 of Hole 332B, then the time of tilting can be determined from this magnetization model as being between 3.5 and 3.3 mybp, the beginning of the Gauss normal epoch. In terms of the present median valley in the FAMOUS area (MACDONALD and LUYENDYK, 1977) tilting would have taken place at the walls of the inner rift valley. The age of the 319-319A set is not sufficiently well known to suggest a particular normal polarity epoch for CRM acquisition.

\section{Conclusions}

It is shown that CRM is the dominant type of magnetization of upper oceanic layer 2 basalts. This is in contrast with earlier suggestions that TRM was the dominant form of magnetization. However, regardless of the widespread occurrence of CRM, original cooling TRM directions are generally well preserved, as is required in the current model for linear magnetic anomaly generation. Small $\left(\$ 10^{\circ}\right)$ changes in inclinations are likely to occur during CRM acquisition and the sense and magnitude of changes appear to depend on the relationship of the original magnetization to the reversal history during the period of alteration.

I would like to thank Mary Ann Annand and Margaret Odell for typing and Alice Scott for drafting. The research leading to this paper was supported by National Research Council of Canada grants A-7812, T-0475 and D-53.

\section{REFERENCES}

Cox, A., Geomagnetic reversals, Science, 163, 237-245, 1969.

HALL, J.M., Age variation in the magnetic properties of oceanic crust, EOS, Trans. Am. Geophys. Union, 58, 377-378, 1977.

HALl, J.M. and P.J.C. RYAll, Paleomagnetism of basement rocks, Leg 37. in Initial Reports of the Deep Sea Drilling Project Leg 37., edited by W. Melson and F. Aumento et al., U. S. Government Printing Office, Washington, D.C., 1977.

Hyndman, R.D., R.P. von Herzen, A.J. Erickson, and J. Jolivet, Heat flow measurements in deep crustal holes on the Mid-Atlantic Ridge, J. Geophys. Res., 81, 4053-4060, 1976.

Irving, E., J.K. PARK, S.E. HAGgerty, F. Aumento, and B.D. LonCArevic, Magnetism and opaque mineralogy of basalts from the Mid-Atlantic Ridge at $45^{\circ} \mathrm{N}$, Nature, 228, 974-976, 1970.

Johnson, H.P. and T. Atwater, Magnetic study of basalts from the Mid-Atlantic Ridge, Lat. $37^{\circ} \mathrm{N}$, Bull. Geol. Soc. Am., 88, 637-647, 1977.

Johnson, H.P. and J.M. HALL, A detailed rock magnetic and opaque mineralogy study of basalts from the Nazca Plate, Geophys. J. R. Astron. Soc., (in press).

Johnson, H.P. and R.T. Merrill, Low temperature oxidation of a titanomagnetite and the implications for paleomagnetism, J. Geophys. Res., 78, 4938-4949, 1973.

LowRIE, W.R., Oceanic basalt magnetic properties and the Vine and Matthews hypothesis, Geophys. $J .$, 40, 513-536, 1974.

LowRIE, W.R., Intensity and directions of magnetization in oceanic basalts, J. Geol. Soc., London, 133, 61-82, 1977.

LOWRIE, W.R., R. Lovlie, and N.D. Opdyke, Magnetic properties of Deep Sea Drilling Project basalts from the north Pacific Ocean, J. Geophys. Res., 78, 7647-7660, 1973a.

Lowrie, W.R., R. Lovlie, and N.D. OPDYKe, The magnetic properties of Deep Sea Drilling Project basalts from the Atlantic Ocean, Earth Planet. Sci. Lett., 17 338-349, 1973 b. 
Macdonald, K.C. and B.P. Luyendyk, Deep-tow studies of the structure of the Mid-Atlantic Ridge crest near latitude $37^{\circ} \mathrm{N}$, Bull. Geol. Soc. Am., 88, 621-636, 1977.

MARShAll, M. and A. Cox, Effect of oxidation on the natural remanent magnetization of titanomagnetite in suboceanic basalt, Nature, 230, 28-31, 1971.

Melson, W., F. Aumento et al., Initial Reports of the Deep Sea Drilling Project, Vol. 37, U. S. Government Printing Office, Washington D.C., 1977.

Merrill, R.T., Magnetic effects associated with chemical changes in igneous rocks, Geophys. Surv., 2, 277-311, 1975.

Mubhlenbachs, K., Oxygen isotope geochemistry of rocks from the Deep Sea Drilling Project Leg 37, Can. J. Earth Sci., 14, 771-776, 1977.

OzImA, M. and M. Ozima, Characteristic thermomagnetic curve in submarine basalts, J. Geophys. Res., 76, 2051-2056, 1971.

Ryall, P.J.C., J.M. Hall, J. Clark, and T. Milligan, Magnetization of oceanic crustal layer 2results and thoughts after Deep Sea Drilling Project Leg 37, Can. J. Earth Sci., 14, 684-706, 1977.

SCHAEFFER, R.M. and E.J. SchwARZ, The Mid-Atlantic Ridge near $45^{\circ} \mathrm{N}$, IX. Thermomagnetics of dredged samples of igneous rocks, Can. J. Earth Sci., 7, 268-273, 1970.

WAYMAN, M.L. and M.E. Evans, Oxide microstructures and the magnetic properties of Leg 37 basalts, Can. J. Earth Sci., 14, 656-663, 1977.

Watkins, N.D. and T.P. PASTER, The magnetic properties of igneous rocks from the ocean floor, Philos. Trans. R. Soc., London A, 268, 507-550, 1971.

WiLson, R.L. and P.J. SMITH, The nature of secondary natural magnetizations in some igneous and baked rocks, J. Geomag. Geoelectr., 20, 367-380, 1970.

Yeats, R.S., S.R. HART et al., Initial Reports of the Deep Sea Drilling Project, Vol. 34, U. S. Government Printing Office, Washington D.C., 1976. 